\title{
Convergence Justifications Within Political Liberalism: A Defence
}

\section{Paul Billingham}

This is an Accepted Manuscript version of an article forthcoming in Res Publica.

\begin{abstract}
According to political liberalism, laws must be justified to all citizens in order to be legitimate. Most political liberals have taken this to mean that laws must be justified by appeal to a specific class of 'public reasons', which all citizens can accept. In this paper I defend an alternative, convergence, model of public justification, according to which laws can be justified to different citizens by different reasons, including reasons grounded in their comprehensive doctrines. I consider three objections to such an account - that it undermines sincerity in public reason, that it underestimates the importance of shared values, and that it is insufficiently deliberative - and argue that convergence justifications are resilient to these objections. They should therefore be included within a theory of political liberalism, as a legitimate form of public justification. This has important implications for the obligations that political liberalism places upon citizens in their public deliberations and reason-giving, and might make the theory more attractive to some of its critics, particularly those sympathetic to religious belief.
\end{abstract}

Keywords Political liberalism · Public justification · Respect $\cdot$ Sincerity

Political liberals believe that laws must be justified to all citizens by reasons they can accept. Most take this to mean that laws must be justified by the same reasons - by reasons that all citizens can accept. In fact, however, 'there can be convergence on a law without consensus with respect to the reasons for that law' (Eberle 2007, p. 435). While some theorists have argued that such 'convergence justifications' should be recognised as legitimate forms of public justification (Gaus and Vallier 2009; Vallier 2011b, 2014), this remains a minority position, requiring further defence from several important objections. In this paper I defend convergence justifications from three such objections, pertaining to sincerity, shared values, and deliberation.

Endorsing convergence justifications as legitimate has significant implications for political liberalism. For example, it provides new resources to respond to the common criticism that political liberalism is inhospitable to religious groups. ${ }^{1}$ Under convergence, religious reasons can play a role in justifying laws,

P. Billingham

St Anne's College and Department of Politics and International Relations, University of Oxford, UK 
and political liberalism's implications for religious citizens are much less restrictive than is commonly thought.

I further outline political liberalism and the implications of accepting convergence justifications in the next section, before responding in turn to the three objections, which each claim that our theory of public justification should only permit consensus justifications.

\section{Political Liberalism, Consensus, and Convergence}

Political liberals believe that the exercise of political power must be justified to those subject to it, by reasons they can accept. Most political liberals ground this claim on the fundamental premise that respect for persons demands that coercion be justified to the coerced. ${ }^{2}$ If individuals within liberal democracies are to be shown respect as free and equal citizens then the coercive laws that they are subject to must be justified to them. This is what distinguishes legitimate collective authority from brute force. Coercion by law is impermissible unless each (reasonable ${ }^{3}$ ) citizen is given reasons to accept it. This can be stated as the Public Justification Principle (PJP): $L$ is a justified coercive law only if every reasonable citizen has reason to endorse it. ${ }^{4}$

As James Boettcher and Jonathan Harmon note, making this connection between respect for persons and public justification is the 'standard approach' within political liberalism (Boettcher and Harmon 2009, p. 8). For example, Lawrence Solum writes that 'respect for citizens as free and equal does mean that we should give our fellow citizens the sort of reasons that they could reasonably accept' (Solum 1993, p. 736). George Klosko argues that governments not basing coercion on grounds citizens can reasonably reject is 'part of what it means to treat people with adequate respect' (Klosko 2003, p. 169). Jonathan Quong concurs: 'respect for persons requires that they not be politically coerced on grounds that they cannot reasonably accept' (Quong 2004, p. 246). Thus, 'respect for persons lies at the heart of political liberalism' (Larmore 1999, p. 606)..$^{5}$

\footnotetext{
e-mail: paul.billingham@politics.ox.ac.uk

${ }^{1}$ Useful overviews are Boettcher and Harmon (2009); Weithman (1997).

${ }^{2}$ Bird (2014) criticises this 'coercion-based' account of political liberalism, but it remains the standard approach in the literature, so I will assume it here. Many of my arguments could be adapted so as to apply to theories that see something other than coercion as triggering the demand for public justification.

${ }^{3}$ This qualification is assumed throughout. Precisely what is required for a citizen to be 'reasonable' is controversial. Such a caveat is necessary, but I take no position here on what it entails.

${ }^{4}$ My formulation of PJP is based on Gaus and Vallier's (2009, p. 53), but is more ecumenical than theirs. PJP is a necessary, not sufficient, condition for legitimacy. Other necessary conditions might include democratic enactment and constitutionality.

${ }^{5}$ Rawls does not make this explicit, but Larmore $(1999,2003)$ argues that respect is fundamental to Rawls's thought.
} 
Some political liberals, most notably John Rawls, apply PJP only to 'constitutional essentials and matters of basic justice' - to questions about basic rights and liberties and basic economic and social justice (Rawls 2005, p. xlviii, fn. 23). For Rawls, legal coercion is legitimate 'when it is exercised in accordance with a constitution the essentials of which all citizens as free and equal may reasonably be expected to endorse' (Rawls 2005, p. 137). Others, such as Quong, contend that PJP applies to all laws (Quong 2004). Constitutional essentials must satisfy PJP because coercion must be justified to the coerced, and this argument equally applies to all other coercive laws. This is reflected in my formulation of PJP. In this paper I assume that PJP must be fulfilled by every coercive ${ }^{6}$ law, but my arguments for the legitimacy of convergence justifications equally apply to the more restricted application of PJP.

Political liberals disagree as to precisely what it means to offer citizens reasons they 'can accept' (or 'cannot reasonably reject'), but all agree that citizens need not be offered reasons that they currently accept in order for coercion to be justified. Citizens must be offered reasons which they could in principle accept, or acknowledge as having normative force, under some level of idealisation. My own view of what this involves will emerge over course of the paper.

The vital point for our purposes is that most political liberals believe that PJP excludes religious reasons, and reasons derived from other comprehensive doctrines, from playing a role within public justification. Crudely put, the argument is that in order for laws to be justified to every citizen they must be justified by reasons that all citizens 'can accept' (however this is interpreted) - by 'public reasons'. Given reasonable pluralism, reasons arising from comprehensive doctrines are non-public, since they cannot be accepted by every citizen. Thus, such reasons cannot be used to justify laws.

This argument is fallacious, however, as can be seen by distinguishing between consensus and convergence justifications. A consensus justification occurs when a law is justified to every citizen by the same reason(s). There is a (set of) reason(s) that all citizens can accept, which justifies the law. A convergence justification occurs when a law is justified to every citizen, but different citizens (or groups of citizens) have different reasons to accept it. The law is justified to different (groups of) citizens by different considerations, and there is no one justifying reason that all accept. Utilitarians believe that the law increases utility, Christians believe it is in accord with the Bible, and Scanlonians believe it satisfies the constraints of contractualism. In this way, the law is justified to every citizen, and yet the overall justification is based upon several comprehensive doctrines. Religious (and other comprehensive) reasons can play a role within convergence justifications, as part of the network of reasons that serve to justify laws to every citizen.

\footnotetext{
${ }^{6}$ All future references to 'laws' should be taken to mean 'coercive laws'. Some theorists believe that all laws are coercive. I take no position on this here. PJP applies to all coercive laws, whether or not every law is coercive.
} 
As it stands, PJP is neutral between consensus and convergence justifications. It allows both as legitimate forms of public justification. It is therefore false to claim that the requirement that laws be justified to every citizen itself excludes religious reasons from public justification. As Gerald Gaus and Kevin Vallier write, 'even if they are not shared by all, religious reasons can enter into a network of justificatory relations, crisscrossing and overlapping diverse reasonable viewpoints to secure an overall public justification' (Gaus and Vallier 2009, p. 61).7

Under a convergence justification, each citizen is given reasons they can accept for the law, so PJP is fulfilled, and coercion is legitimised by this fact. ${ }^{8}$ Every citizen is shown respect as a free and equal member of the polity, since the coercion they face is justified to them. At first glance, therefore, there appears to be no reason to reject convergence as a legitimate form of public justification. This has important implications for political liberalism.

Two obligations fall upon citizens if only consensus justifications are legitimate. ${ }^{9}$ First, since there is a specific set of reasons that must be used within public justification, those that can be accepted by every citizen, citizens have an obligation to provide such reasons when advocating a law. They must provide public reasons to their compatriots, in order to justify the law to them. 'When citizens engage in political advocacy, they have a moral duty to justify their decisions according to public reasons that others can reasonably accept' (Schwartzman 2011, p. 375). This is the 'public-reason-giving requirement'. ${ }^{10}$

Second, citizens should refrain from supporting laws for which they have only non-public reasons unshared reasons, such as those arising from their comprehensive doctrines. Most political liberals accept what Boettcher calls 'weak inclusionism' (Boettcher 2005, pp. 498-500), so hold that citizens are morally permitted to offer their comprehensive reasons in public deliberation, but only if they also offer sufficient public reasons for laws they advocate. ${ }^{11}$ Thus, if the only reasons a citizen has for endorsing a law are nonpublic then she ought not support it, since these reasons cannot publicly justify laws. This is the restraint requirement (Eberle 2002, pp. 68-71).

The legitimacy of convergence justifications makes these implications for citizen conduct much less clear. There is no longer a specific class of reasons that must be used in public justification, so there cannot be a

\footnotetext{
${ }^{7}$ This also applies to secular comprehensive reasons.

${ }^{8}$ These reasons must be 'conclusive', or 'sufficient', as I explain below.

${ }^{9}$ Some consensus theorists argue that these obligations only apply to officials, not to ordinary citizens. See Habermas (2006); Laborde (2013).

${ }^{10}$ This term is from Stears and Humphrey (2012, p. 287).

${ }^{11}$ Rawls's (2005, pp. 462-463) 'proviso' is an example of this.
} 
public-reason-giving requirement. There can also be no simple restraint requirement, since all of the reasons a citizen can accept can be part of a law's public justification. Even if the only reasons an individual has for supporting a law are ones that arise from her comprehensive doctrine, the law might be justified to others by their own reasons. If citizens exercised restraint in such cases then some laws might not be enacted which could in fact be publicly justified. ${ }^{12}$ 'Strong inclusionism', where no restraint is required, is thus correct. Citizens should support any law they wish, appealing to any reasons they believe are relevant to its justification. ${ }^{13}$

There might be reasons for us to reject convergence justifications, however. Although PJP allows them, perhaps there are arguments which show that they are not legitimate forms of public justification. I will consider three. The first is that convergence permits insincerity in citizens' advocacy, allowing them to manipulate one another. The second is that the value of public justification partly derives from the shared purposes and unity it encourages in society, which are undermined by convergence. The third is that convergence is insufficiently deliberative.

I will discuss, and reject, these objections in turn. Convergence is resilient to them, so should be accepted as a legitimate form of public justification, with all the implications this brings. ${ }^{14}$

\section{The Sincerity Requirement}

Political liberalism should include a sincerity requirement, according to which citizens should not support laws that they know others lack reasons to endorse. ${ }^{15}$ This is important because it prevents manipulation. Betty might believe that a law is justified to her, based on information that Alf knows to be false. If Alf supports the law despite knowing that it cannot in fact be justified to Betty then he manipulates her. She accepts the law as justified to her, but is wrong to do so, and Alf plays on this fact in presenting the law as publicly justified. This is disrespectful. It shows a willingness for others to be coerced in ways that cannot be justified to them, so fails to show adequate respect for them as free and equal. The sincerity requirement therefore states that $A$ may support law $L$ only if two conditions are satisfied: ${ }^{16}$

\footnotetext{
${ }^{12}$ This is not to imply that every publicly justified law must be enacted, but that there will be some publicly justified laws which are not known to be so. Awareness that they could be legitimately enacted is lacking.

${ }^{13}$ There might be a minimal proposal-restraint requirement, stating that a citizen should not support laws she knows cannot be publicly justified and that are likely to be enacted if she supports them. See Vallier (2014, pp. 184-190); Gaus (2009).

${ }^{14}$ In the absence of further objections not considered here.

${ }^{15}$ At least in cases where it is likely the law will then be enacted - see $\mathrm{fn}$. 13. Even when the law is unlikely to be enacted, it would be insincere to claim that a law is publicly justified when one knows it cannot be justified to some fellow citizen(s). I put these complications to one side, since they do not affect my arguments.

${ }^{16}$ This is based on Quong (2011, p. 266). I have amended (ii), however. Quong's (ii) says that A must reasonably believe that $\mathrm{B}$ is justified in endorsing $\mathrm{L}$. This is problematic, since citizens are unlikely to know whether every fellow
} 
(i) A believes he is justified in endorsing $L$.

(ii) A does not believe that $L$ cannot be justified to $B$.

Quong (2011, pp. 265-273) argues that this requirement is not fulfilled when laws only have convergence justifications. Suppose Alf supports $\mathrm{L}$ based solely on $\mathrm{R} a$ and Betty supports $\mathrm{L}$ based solely on $\mathrm{R} b$, where $\mathrm{R} a$ and $\mathrm{R} b$ are reasons derived from their respective comprehensive doctrines. Alf rejects $\mathrm{R} b$ and Betty rejects $R a$, since they each regard the other's comprehensive doctrine as false. Alf therefore believes that $L$ is not justified to Betty. Alf recognises that Betty believes $L$ is justified to her, but Betty does so based on a false belief $(\mathrm{R} b)$. The reasoning from Betty's comprehensive doctrine to $\mathrm{R} b$ might be flawless, but Alf rejects Betty's comprehensive doctrine, so thinks that $\mathrm{R} b$ is false, and is not a reason for Betty. It is therefore disrespectful and manipulative for Alf to support L. Condition (ii) is not met, so Alf should not support L. ${ }^{17}$ The same is true, of course, of Betty's view of Ra. Neither Alf nor Betty can sincerely support L 'because each person must believe the other is not justified in endorsing' it (Quong 2011, p. 267).

In order to be publicly justified, laws must be justified to every individual. To defend convergence justifications from this objection, one must argue that it is possible for $\mathrm{R} b$ to be a reason for Betty, and for Alf to be able to recognise it as such, even though it is not a reason for Alf, who believes it to be false. Alf thus believes that $\mathrm{L}$ can be justified to Betty, by $\mathrm{R} b$, so condition (ii) is satisfied and Alf can sincerely support L.

Charles accepts the Torah as authoritative, and on this basis believes it would be wrong for him to eat pork. ${ }^{18}$ Deborah rejects the authority of the Torah, so does not believe that Charles would be wrong to eat pork. Nonetheless, she might accept that Charles's Jewish faith gives him a reason not to eat pork. Not eating pork is justified to him, given his beliefs. Deborah accepts that Charles has a valid reason, even though she believes it is false. It is rational for him to act on this reason, given his comprehensive doctrine. This appears to be the kind of case we need.

This example involves a conception of reasons and justification which Quong explicitly rejects: 'justification requires more than impeccable inferences - it also requires sound premises' (Quong 2008, p. 5). Deborah believes Charles's premises are false, so cannot believe he is justified in believing he should not eat pork. However, this conflates rational justification and soundness. As Eberle argues, 'soundness has to do with the objective adequacy of an argument for a given conclusion; rationality has to do with

citizen is justified in endorsing a law. Instead, the requirement should be that they shouldn't support laws that they know cannot be justified to some fellow citizen(s).

${ }^{17}$ For similar arguments, see Bohman and Richardson (2009, pp. 269-270); Audi (1997, pp. 135-136). Schwartzman (2011) is a full discussion of sincerity in public reason.

${ }^{18}$ Quong (2008, pp. 5-6) gives a similar example. 
whether some argument appears to be sound given a citizen's evidential set and given that she has gone about evaluating that argument in the appropriate manner' (Eberle 2002, p. 62). Eberle here identifies two aspects of rational justification. First, it primarily concerns the manner in which one forms a belief. It requires one to subject one's convictions to criticism, seek good evidence, and respond to that evidence appropriately, changing one's beliefs where appropriate. Second, rational justification depends on the beliefs and experiences one already has, since these are the only bases on which one can evaluate evidence and reasons.

Given his experience and available information, Aristotle was rationally justified in believing that the sun orbited the earth, just as I am rationally justified in believing the reverse. Aristotle might have used impeccable reasoning, but he applied it to false premises and thus reached a false conclusion. Nonetheless, he was justified in his belief. Quong's statement that justification 'requires sound premises' implies that I cannot regard Aristotle's belief as justified, but this is surely incorrect.

We can refer to Eberle's conception of justification as 'open justification'. To openly justify a proposition to John, one must 'show that it can be properly inferred from John's present belief-value set conjoined with adequate information, reasoning ability and some degree of belief coherence' (Vallier 2011a, p. 112). John's belief-value set is the set of all his beliefs, experiences, goals etc. ${ }^{19}$ A proposition is not openly justified to him simply if he believes it. After all, he might have reasoned badly or lack easily attainable relevant information, or his belief-value set might contain plain contradictions which prevent him from believing the proposition in question. We should correct for these mistakes, imputing to agents easily attainable relevant information and correcting any obvious errors in their reasoning. This 'moderate idealisation' forms the 'admirably rational' version of an agent (Vallier 2011a, pp. 211-284; Gaus 2011, pp. 232-257). ${ }^{20} \mathrm{~A}$ law is justified to an agent when their admirably rational counterpart has reason to accept it; in other words, when the agent is openly justified in accepting reasons that justify the law.

Others will often recognise that a belief is openly justified to an individual. Deborah can appreciate that Charles's belief regarding pork is inferable from his belief-value set. In this way, the belief is intelligible to her. She regards it as misguided, but can recognise that it provides a reason for him: it is openly justified to him.

\footnotetext{
${ }^{19}$ Eberle calls this one's 'evidential set'.

${ }^{20}$ There is clearly ambiguity in terms like 'easily attainable' empirical information and 'obvious errors' in reasoning. Different specifications of these terms give different levels of idealisation. The precise specifications do not matter for my argument here.
} 
Quong can acknowledge that open justification is a legitimate type of justification. ${ }^{21}$ But he contends that public justification requires that we believe that others are actually justified in their beliefs, 'justified full stop', rather than merely openly justified. This is because sincerity attaches to actual justification. Even if Alf recognises that Betty is openly justified in endorsing $\mathrm{L}$, based on $\mathrm{R} b$, he cannot sincerely believe that $\mathrm{L}$ is justified to Betty. From Alf's point of view, L cannot be justified to Betty, since Betty's only reason for endorsing $\mathrm{L}$ is $\mathrm{R} b$, which Alf rejects. If another is merely openly justified in endorsing a law, then I consider them to be unjustified, so cannot sincerely support the law. I will argue that this is incorrect; the requirements of sincerity and respect can be fulfilled by open justification.

Open justification invokes an internalist conception of what it is for an individual to have a reason: reasons are relative to one's current belief-value set. Charles can therefore have a reason in circumstances $C$ that Deborah lacks, given their different belief-value sets. Charles has reason not to eat pork, since he accepts the authority of the Torah, whereas Deborah does not. Steven Wall rejects this in favour of an externalist conception, according to which all individuals in the same circumstances have the same reasons to act (Wall 2010, pp. 134-135). These reasons are those that would be accepted by a fully rational agent: an agent who knows all relevant factual information, reasons flawlessly, and knows of all the evaluative considerations that apply and their relative weights. In this sense, Charles might not have reason to refrain from eating pork - i.e. if the Torah is not in fact the authoritative word of God. ${ }^{22}$ The question for us is what kind of reasons are relevant to public justification. The answer must come from what is required by respect for persons, the value underlying political liberalism.

Respect for persons requires us to offer explanations for coercion that are addressed to the coerced individual(s): reasons they can accept. An externalist conception of reasons prevents this. According to externalism, Alf can support law $L$ as long as he believes that he is warranted in believing $L$ to be justified and that a fully rational version of Betty would also believe this. Thus, William Galston claims that we respect others by offering them 'as explanation, what we take to be our true and best reasons' (Galston 1991, p. 109). We present the truth as we see it, and this is enough to justify coercion.

This fails to respect people as they are, with their current beliefs and values. Others might believe themselves to have no reason to accept the law as justified, since the beliefs, information or reasoning we base our justification upon are rejected by them, or beyond their comprehension. Coercion interferes with others' capacity to act by their own lights. We cannot justify this simply by appealing to our own reasons, but must engage with the coerced person's viewpoint and seek to offer reasons they can accept (Eberle

\footnotetext{
${ }^{21}$ At one point Quong (2011, p. 142, fn. 11) explicitly says that individuals can be justified in believing falsehoods, if they reason blamelessly but reach false conclusions due to their limited epistemic situation.

${ }^{22}$ And if all other arguments against meat-eating are mistaken. I am not endorsing this view here.
} 
2002, pp. 98-99). Further, it is not enough to say that they would accept this reason were they fully rational. Even if we can plausibly claim that a fully rational and informed version of Betty would accept the reason Alf offers to justify L, this explanation fails to address Betty. Justification is offered not to Betty herself, but to a non-existent radically idealised Betty, who might have very different beliefs to actual Betty. Moderate idealisation is necessary, to correct for obvious errors in reasoning or a lack of easily attained empirical information. Any changes this makes to citizens' belief-value sets are epistemically accessible to them, imputing reasons they could themselves recognise if they engaged in a respectable amount of deliberation (Gaus 2011, pp. 244-257). Radical idealisation, justification based on what fully rational agents would accept, lacks these features, so is unacceptable.

Quong's interpretation of the sincerity requirement takes things in the opposite direction: Alf can only justify laws to Betty using reasons that Betty accepts and that Alf also believes are sound. Shared reasons are needed for public justification. This also fails to respect people as they are, since it denies the relevance of the fact that others can have rationally justified beliefs based upon considerations we reject. It is not insincere for Alf to recognise that from Betty's perspective $L$ is justified by $R b$, which Betty is openly justified in accepting given her belief-value set, even though Alf himself rejects $R b$, since it is not openly justified by his belief-value set. This simply reflects the fact that Alf's belief-value set does not determine what is (openly) justified to Betty. Accepting this fact is necessary if political liberalism is to adequately respect pluralism. People's different comprehensive doctrines mean that they have different values and beliefs - different evaluative standards - which give rise to different internalist reasons, reasons openly justified to an individual. Citizens must recognise these reasons if they are to respect one another as agents holding to different conceptions of the good. This does not require believing these reasons to be true in the externalist sense, ${ }^{23}$ but it does mean believing them to be openly justified to the individual concerned and that they can justify laws to those individuals. Not doing this expresses a form of disrespect. Contra Quong, respecting our compatriots means that sincerity attaches to open justification: we can sincerely believe that another is justified in endorsing a law when we recognise that they are openly justified in doing so. ${ }^{24}$

Imagine a society deciding whether to implement a safety net providing income to the long-term unemployed. A Nozickian might support this law based on her belief that without it the long-term unemployed would be in a worse position than in the state of nature prior to appropriation, violating Nozick's version of the Lockean proviso (Nozick 1974, pp. 174-182). A Rawlsian might support the law

\footnotetext{
${ }^{23}$ i.e. Alf doesn't have to believe that $\mathrm{R} b$ would be accepted by a fully rational individual. Presumably Alf believes that his reasons are true in this sense, since he believes his comprehensive doctrine is true, but he cannot believe that reasons arising from others' comprehensive doctrines are true in this sense.

${ }^{24}$ As Vallier (2011b, p. 262) writes, 'only by embracing convergence can public reason liberals truly respect reasonable pluralism and individual liberty.'
} 
because he believes it contributes to the fulfilment of the difference principle (Rawls 1999, pp. 52-73). A Christian might support it because it is in line with Biblical injunctions to help the poor (such as Deuteronomy 14:28-15:11 and Isaiah 58:6-10). There is thus a convergence justification for the law. Importantly, each individual believes that the law is actually justified, each for their own reasons. Condition (i) is met. They also can each recognise that others are openly justified in endorsing the law, since they can recognise that others have reason for doing so from within their belief-value sets, so condition (ii) is met. There is no insincerity involved in them each admitting these facts, and supporting the law on this basis. ${ }^{25}$

If this is right, why can't we go further? Vallier and Gaus both argue that the reasons which justify the law to others must be intelligible to us to legitimately be part of a public justification (Vallier 2011a, pp. 145147; Gaus 2011, pp. 289-292). We must be able to recognise that they are reasons for them, that they are openly justified to them given their belief-value set. If justification is perspectival, however, then shouldn't we simply accept others' word? If Betty claims that $L$ is justified by reason $\mathrm{R} b$ then maybe this should be enough for Alf, even if Alf cannot understand this claim, so believes that the law cannot be justified to Betty. Perhaps Alf does not understand how R $b$ justifies $L$, or how $\mathrm{R} b$ can be inferred from Betty's other beliefs, or how it is supported by the evidence that Betty points to. But Betty believes the law to be justified, so this is enough.

This does fall foul of the sincerity requirement. If Betty accepts $\mathrm{R} b$ due to empirical information that Alf knows to be false, then it is insincere for Alf to claim that $R b$ justifies $L$ to Betty. If a modern-day Aristotle believed that the sun orbited the earth then it would be disrespectful to justify coercion to him by appeal to this belief, since we know it to be empirically false. It is no longer possible for an agent to be openly justified in believing that the sun orbits the earth. There is easily attainable empirical evidence that conclusively proves that this is not the case, and thus no admirably rational agent believes it.

Similar considerations apply in cases where Alf rejects Betty's reasoning to Rb from Betty's belief-value set, or from $\mathrm{R} b$ to $\mathrm{L}$. If Alf cannot understand this reasoning, or can see obvious flaws in it, then he cannot sincerely hold $\mathrm{L}$ to be justified to Betty based on it. He believes that a moderately idealised Betty would not accept $\mathrm{R} b-\mathrm{R} b$ is not openly justified to Betty, so cannot justify $L$ to her. Alf might well be right about this. Or it might be that Betty is openly justified, but for some reason Alf cannot recognise this. In either case, claiming that a law is justified to someone based on their word even though one cannot comprehend how this is the case fails to take them seriously as a person who should not be coerced lightly. If one believes that a law cannot be justified to another then imposing it upon them is

\footnotetext{
${ }^{25}$ For support for 'ad hoc justification', where different citizens are offered different reasons for a law, see Wolterstorff (1997, pp. 106-107); Swaine (2009, pp. 191-193); Stout (2004, pp. 72-73); Eberle (2007, pp. 434-435).
} 
disrespectful. This is why there must be an intelligibility requirement; one must recognise that a law is openly justified to another agent in order to sincerely claim that they are justified in endorsing it. ${ }^{26}$

Convergence justifications can fulfil the sincerity requirement. As long as $\mathrm{R} b$ is intelligible to Alf and $\mathrm{R} a$ is intelligible to Betty, they can both sincerely support $L$, despite lacking shared reasons. ${ }^{27} \mathrm{~L}$ is justified to both individuals by reasons they accept, and they can each recognise that $L$ is justified to the other, so the sincerity requirement is fulfilled.

\section{Shared Values and Social Unity}

A second objection to convergence justifications is that they fail to incorporate an important aspect of public justification: shared values. For many theorists, one of the central attractions of political liberalism is that it creates a polity united by a set of values and principles that all can endorse. Stephen Macedo states that political liberals seek 'political principles that can be publicly justified and widely affirmed by reasonable people in a diverse society' (Macedo 1997, p. 2). Requiring consensus justifications ensures that citizens justify laws by appeal to values that all can accept, thus creating a polity unified around shared motivations for political action. Consensus is not simply on each law, but also on the values underlying the laws.

Convergence justifications lack this dimension. Laws are justified to citizens by diverse reasons and values. Each accepts laws for her own reasons, which may not be shared by others. While it is likely that subgroups within society share values that they draw on to justify laws, there need not be any political principles accepted by all citizens. Permitting convergence removes an important aspect of political liberalism's appeal. ${ }^{28}$

\footnotetext{
${ }^{26}$ This point can also be made using Swaine's (2009, pp. 194-196) distinction between inaccessible and incomprehensible reasons. Inaccessible reasons are openly justified to another individual, but rely on experiences one lacks or premises one rejects. They are intelligible; one can see that they are openly justified to the other. Incomprehensible reasons are simply impenetrable; one cannot make sense of them. They are unintelligible. Appeal to another's inaccessible reasons isn't disrespectful; appeal to their incomprehensible reasons is.

${ }^{27}$ As a reviewer rightly noted, there are difficult questions here about precisely when another's beliefs are, or are not, intelligible. He/she offered a case where Betty bases a belief on 'mystical perception' of God's commands (on which, see Eberle (2002, pp. 239-251)). I cannot offer a full reply to such cases, but the most important point to note is that intelligible open justification does not require that we believe others' basic evaluative standards, or worldview, to be sound, or all-things-considered justified. Quong (2011, pp. 271-272) rightly argues that we should not expect this of citizens. Instead, intelligible open justification centres on whether we can recognise that others' beliefs are justified to them given their evaluative standards. If Betty's belief in mystical perception is part of a broader, reasonably coherent, worldview, then I think that it can be intelligible, even if Alf considers it misguided. Using Swaine's distinction, the belief is inaccessible to Alf, but not incomprehensible.

${ }^{28}$ Macedo (2010) argues along these lines. My discussion differs from, but does not contradict, Vallier's (2011b) reply to Macedo.
} 
As a preliminary response, Vallier notes that 'convergence does not rule out common reasoning; it only allows diverse reasoning' (Vallier 2011b, p. 272). Theories that permit convergence can still encourage consensus justifications wherever possible. Convergence justifications are simply also permitted. Shared values and principles can be as common, and appealed to as often, as if we only permitted consensus justifications, and further overlap on laws justified by diverse values is then also encouraged.

To press the objection, one must therefore argue that permitting convergence undermines the benefits of consensus. Society is less unified, since many laws are justified by convergence. Further, shared values themselves might be undermined. They are not necessary for justifying laws, so are no longer the focus of political life, and are not encouraged to the same extent.

Even if this were true, it does not give us reason to favour existing consensus-only theories, because such views permit the enactment of laws that are not justified to all citizens. A law that is justified by appeal to values that all citizens accept might not be justified to all (Wolterstorff 2007, p. 150). Citizens can share a set of values yet disagree on whether they give rise to reasons sufficient to justify a certain law. Permitting the enactment of such laws, as existing consensus theories do, fails to respect all citizens as free and equal. This cannot be justified by potential gains in social unity.

Quong's view provides an example here. Quong (2011, Chapter 6) argues that all reasonable citizens accept three general liberal principles of justice. These are:

(i) All citizens should be assigned basic rights and liberties.

(ii) These rights and liberties should be given special priority.

(iii) All citizens must have adequate all-purpose means to make use of their rights and liberties. Each citizen also endorses some reasonable political conception of justice, which interprets and orders various political values that all accept on the basis of (i)-(iii). This gives a common basis for public decisionmaking. Each citizen can appeal to the balance of shared values within their conception of justice, and any law that is justified by such a conception can be legitimately enacted.

This view permits the enactment of laws that are not justified to all. Anthony and Belinda both have reasons for and against law L, arising from their respective (reasonable) conceptions of justice, Ja and $\mathrm{J} b . \mathrm{L}$ has egalitarian merits, but would also restrict freedom of choice. On balance, Anthony considers $L$ to be justified, while Belinda considers it to be unjustified, because $\mathrm{J} b$ places less weight on equality than Ja does. Belinda believes L's restriction of freedom is too great to justify the reduction in inequality. She has decisive reason to reject the law, so the coercion it involves is not justified to her. On Quong's account, however, $L$ can be legitimately enacted, since there is a reasonable balance of political values according to 
which it is justified (i.e. Anthony's). The fact that the law is not justified to Belinda does not stop it being enacted.

Quong would respond to such examples by arguing that the law is in fact justified to Belinda in the relevant sense, by drawing on his distinction between 'foundational' and 'justificatory' disagreements. If a law is justified solely by appeal to a particular conception of the good then those who reject the law have a 'foundational disagreement' with the law's advocates. They do not 'share any premises which can serve as a mutually acceptable standard of justification' (Quong 2011, p. 193). They lack any shared values by which their dispute can be adjudicated. In effect, those who reject the law have been offered no reasons in its favour, since a controversial conception of the good cannot provide a mutually acceptable standard of justification.

The case is very different, for Quong, when a law is justified by appeal to a reasonable political conception of justice, even one that some citizens reject. The disagreement in this case is 'justificatory', because reasonable citizens share a set of values that 'serve as a mutually acceptable standard of justification,' though they 'nevertheless disagree about certain substantive conclusions' (Quong 2011, p. 204). The values used to justify the law are mutually acceptable, even though the parties disagree on the 'exact weight or ranking of those values or principles' (Quong 2011, p. 207), and thus disagree on whether those values support this law. All citizens can recognise that the law is justified by appeal to a plausible balance of values that they accept. It is true that some citizens will interpret or weigh those values differently, and thus reject the law. But their freedom and equality is respected, because their disagreement with those who advocate the law is merely justificatory, not foundational. They can endorse the values used to justify the law, so it is justified to them. ${ }^{29}$

In my view, this account of what is involved in justifying coercion to an individual fails to fulfil the requirements of respect. A coercive law is not justified to an individual when they have conclusive reason to reject it. This is true even if they can recognise that some reasonable interpretation of values they accept supports the law, so their disagreement with its advocates is justificatory. If Charlotte coercively interferes with Donald and offers a justification appealing to a value that Donald accepts, but which in this instance is completely outweighed within his belief-value set, then Charlotte does not show him adequate respect. Charlotte motions toward respect for Donald, engaging with his perspective to some degree, but picks out reasons favouring her interference while ignoring the fact that he has conclusive countervailing reasons. Similarly, Belinda is not shown sufficient respect if $L$ is enacted. According to her conception of

\footnotetext{
${ }^{29}$ In Lister's (2013b) terms, Quong's view applies the 'unanimous acceptability requirement' to the reasons for decisions, rather than to decisions themselves.
} 
justice, $L$ is objectionable, and thus it is not justified to her, even if it is justified according to a different reasonable political conception.

Our understanding of PJP should include a 'conclusivity requirement'. Citizens must have sufficient reason to endorse a law, so lack decisive reasons to reject it, in order for its imposition upon them to be legitimate. Since his view lacks such a requirement, Quong permits coercion that is not justified to the coerced. The same is true of all theories that claim that appeal to (a plausible balance of) shared values is sufficient to fulfil PJP.

We might amend Quong's account to include a conclusivity requirement, by holding that in order for a law to be publicly justified all citizens' political conceptions of justice must endorse it. All must endorse the law on the basis of their reasonable balances of political values. But this account still fails to truly respect citizens, due to its dismissal from public justification of values that a citizen accepts but are not shared by all others. Based solely on her political conception of justice, Erica views $L$ as just, but her comprehensive doctrine gives her decisive reasons to reject $L$ and consider it unjust. On Quong's view, only shared values count, and all reasonable citizens recognise this priority of political values. However, it is not unreasonable for Erica to object to $L$ based on the fact that it is ruled out by her comprehensive doctrine. ${ }^{30}$ It is disrespectful to claim that $L$ is justified to her by shared values, when her full belief-value set gives her conclusive reason to reject $\mathrm{L}^{31}$

In my view, therefore, laws must be conclusively justified to each citizen on the basis of all of her reasons, taking her full belief-value set into account. ${ }^{32}$ Convergence justifications achieve this, while existing theories that require shared values do not.

The 'conclusivity requirement' might seem to have undesirable implications, however. Perhaps few, if any, laws will be conclusively justified to every citizen, and thus convergence political liberalism will lead to an ultra-minimal state, or even to anarchism. If an interpretation of what respect for persons demands with regard to the justification of coercion inevitably rules out almost all laws as illegitimate, then that interpretation is surely implausibly strong.

\footnotetext{
${ }^{30}$ Note that Erica is not here imposing her comprehensive doctrine on others, or arguing that it provides reasons for them, merely that it provides reason for her to reject $\mathrm{L}$.

${ }^{31}$ Gaus and Vallier (2009, pp. 62-65) call a refusal to allow religious reasons to act at defeaters the 'error of symmetry'.

32 I am drawing on the internalist understanding of reasons that I defended in the previous section here. If Quong's interpretation of the sincerity requirement was correct, then shared values would be necessary for public justification. My arguments in this section thus depend on the success of my arguments in the previous section.
} 
Whether the conclusivity requirement does have such implications depends on how it is interpreted. If a citizen must consider a law to be the best possible law in order for it to be conclusively justified to her, then we will certainly get anarchistic results. No law would be considered optimal by every citizen. This is an implausible interpretation of conclusivity, however. Much more plausible is Gaus's (2010b, pp. 195197) claim that a law is conclusively justified to a citizen when, according to her (moderately idealised) belief-value set, it is an improvement on having no law on this issue. This means that she prefers this coercive law to facing no such coercion, and thus it is justified to her. The conclusivity requirement is violated when citizens have decisive reasons to reject laws, such that they view a law as being worse than having no such law.

The implications of this view ultimately depend upon the beliefs and values of citizens within a polity. Respect for citizens means that laws must be conclusively justified to them on the basis of their own belief-value sets, and therefore it is those belief-value sets that determine what laws are, and are not, publicly justified. There are good reasons to believe that this view would not have anarchistic, or even ultra-minimal state, implications, however, given the many goods that are achieved by social coordination through law (see Gaus 2011). ${ }^{33}$ Gaus (2010a) argues that the convergence view has a 'classical liberal tilt', rendering illegitimate laws implementing high levels of redistribution. While I lack space to show it here, I believe that his arguments for this conclusion are flawed, and Gaus's own view in fact permits more redistribution than he recognises. ${ }^{34}$

So far in this section, I have argued that existing consensus-only views, which do not include a conclusivity requirement, fail to adequately respect citizens as free and equal. Quong's distinction between justificatory and foundational disagreement does not have the normative significance that he claims, so cannot rebut this objection. I have also briefly explained my understanding of 'conclusivity', which follows Gaus's, and why I do not think it leads to an ultra-minimal state.

There is one political liberal view that I have not considered, however, which endorses conclusivity while also seeking to maintain the importance of shared values. According to this view, laws must be conclusively justified to all citizens by their own belief-value sets, and must also be justified by appeal to a reasonable balance of shared values. ${ }^{35}$

\footnotetext{
33 I lack space to defend this claim here. The question of the implications of convergence political liberalism, given this understanding of conclusivity, is an area in which more work is needed from defenders of the view.

${ }^{34}$ For arguments to this effect, see Lister (2013a), Baccarini (2013, pp. 40-49). The implications of convergence political liberalism depend on the precise specification of PJP. For critical discussion, see Lister (2013b, pp. 81-101). Gaus (2010b) replies to some of Lister's arguments.

${ }^{35}$ No theorist has endorsed this view, as far as I am aware.
} 
The implications of this view in terms of what laws are publicly justified are probably very similar to those of convergence political liberalism. Most laws that are conclusively justified to all citizens will have some plausible justification using shared values. An advocate of the view would argue that it achieves a higher level of social unity that convergence political liberalism, however, due to requiring appeals to shared values. This ensures that citizens can recognise common reasons for laws, so are united around shared political purposes.

This argument is mistaken, however. The mere fact that laws are justified by appeal to shared values, in addition to being conclusively justified to all, does not increase social unity, because for many citizens it is not those shared values that actually justify particular laws to them. I might reject the interpretation and weighting of shared values that is used to support a publicly justified law, while nonetheless endorsing the law, because it is conclusively justified to me on the basis of my full belief-value set. While I do not think it is justified by shared values, I have other, comprehensively-based, reasons to endorse it. The law is justified to all, but there is no consensus on the values that underlie it, so no deeper social unity is achieved by the appeal to shared values.

This is not to say that there is disunity in such cases, or that convergence political liberalism denies the value of social unity. The fact that laws are conclusively justified to all itself achieves a valuable ideal of social unity, since it means that all can endorse the laws that they live under together. Further, I am not denying that shared values will be used to justify laws. Indeed, citizens have clear pragmatic reasons to appeal to values that they share with others in order to persuade them of the merits of particular laws. Appeals to both shared and unshared values will be common.

The crucial point, however, is that once we recognise that respect for persons requires that laws are conclusively justified to all, there is no further benefit gained from also requiring that laws are justified by appeal to shared values. Shared values are not necessary for public justification, since laws can be justified to citizens by a diverse range of reasons and values. Further, requiring appeals to shared values in addition to conclusive justification does not achieve any greater degree of social unity, or sense of being united around shared reasons for political action, since it will often not be those shared values that actually justify laws to some, or even many, citizens. Those citizens consider the interpretation of shared values that is used to justify the law mistaken, although they endorse the law on the basis of their full beliefvalue sets.

\section{The Role of Deliberation}


A third objection to convergence justifications is that they undervalue deliberation. They confine the role of public discourse to the discovery of reasons citizens already have, in order to identify whether laws are justified to them. Deliberation is not necessary for public justification; all that is required is that each citizen has sufficient reason to endorse laws. Political liberalism should include a greater role than this for deliberation. Requiring consensus justifications encourages deliberation by obliging citizens to show that their common values can support laws. Citizens deliberate together on the merits of each policy from their shared perspective. Convergence removes this central role of deliberation, so should be rejected.

Quong levels this criticism at Gaus and Vallier, arguing that their exclusive focus on laws being publicly justified gives 'a slightly impoverished conception of public reason's value' (Quong 2008, p. 17). By engaging in the practice of public reason, deliberating over the justification of laws, citizens manifest respect for one another as free and equal, honouring the idea that each is owed justification for the laws they live under. Civic respect is realised by practising public reasoning, not merely by enacted laws being publicly justified.

To asses this objection, we must identify the roles that deliberation should play within political liberalism. Boettcher offers three. First, deliberation enables citizens to understand others' arguments and views. Citizens exchange reasons in order to improve their decision-making and better understand their different claims, arguments, and conceptions of justice' (Boettcher 2007, p. 225). Second, deliberation can change citizens' judgments, as they recognise the force of others' arguments. Citizens 'should be willing to revise their political judgments through discussion and deliberation with others' (Boettcher 2007, p. 225). Third, deliberation should aim at the achievement of justice, or the common good (Boettcher 2005, pp. 503-504).

These three aspects of deliberation are indeed appealing. However, it is not immediately clear how important they are in a theory of public justification. They concern the way in which citizens directly show respect to one another, whereas PJP's immediate concern is that laws be justified to every citizen. Ideals of public reason are almost always justified by an appeal to the need to justify coercion to the coerced, yet this can be fulfilled by only laws that can be justified to every citizen being enacted. ${ }^{36}$ The main value that deliberation appears to have is that it makes information available as to what reasons citizens have in relation to a law. Deliberation is a useful way for all the different reasons for a law to be put forward, in order to identify whether it can be publicly justified. It is thus a means to an end: it is helpful in ensuring that all citizens are respected, by only laws that can be justified to them being enacted.

\footnotetext{
${ }^{36}$ And, perhaps, this public justification being publicly offered.
} 
Nonetheless, we should certainly also require that citizens directly show one another respect in their public interactions. If citizens are to respect one another in their political conduct then they should indeed deliberatively engage with one another, offering and discussing reasons for and against laws, and being ready to change their views. If a publicly justified law is enacted without any deliberation having occurred among the citizenry then no individual has been wronged by being unjustifiably coerced. Yet deliberation remains a central aspect of citizens' obligations, and something which political liberalism should encourage. Does a theory permitting convergence justifications by necessity place too little value on deliberation, so fail to encourage adequate manifestations of respect?

It might appear so. Under convergence, citizens have laws justified to them by different reasons, so deliberation need not aim at identifying shared values and reasons. Citizens are not obligated to deliberate based on a shared perspective, or to demonstrate to others that their shared principles support a law. Thus, deliberation's role is reduced compared to when only consensus justifications are permitted. Public justification consists merely in demonstrating that different reasons can be used to justify the law to each citizen, given their beliefs-value sets.

This analysis is mistaken. Convergence should not take pre-deliberative opinions as fixed. Although the focus is on ensuring that citizens have sufficient reason to endorse laws, this will often be achieved through discussion. A citizen's beliefs can be changed through deliberation, causing her to accept reasons she previously rejected. Sometimes the law will already have been justified to her: her belief-value set already gave sufficient reason for it, although she did not realise this. In many cases, however, her beliefvalue set itself will be changed by deliberation, so laws that were not previously justified to her will come to be so. Persuasion is crucial to the achievement of convergence justifications.

If we permit convergence justifications then we cannot expect any individual citizen to justify laws to all other citizens, showing each that they have reason to support a law. Nonetheless, deliberation is important on a smaller scale. Citizens who advocate a law should seek to persuade those they directly engage with that they have reason to support it. This can be achieved by appeal either to shared values or to idiosyncratic values that one's interlocutors accept. Convergence can thus be more deliberative than consensus. Rather than deliberation being limited to the discussion of shared values and reasons, citizens can engage with others' comprehensive doctrines and seek to show that these provide reasons for laws. Convergence allows citizens to engage with all of each others' reasons, rather than only with those that are shared by all. This encourages more deliberation, rather than less.

Further, deliberation is not necessary for public justification on a consensus view either. The state, or individual citizens, could identify laws that are justified by shared values without participating in 
deliberation. As long as a citizen believes that public reasons justify a law, they can legitimately support it and it can be legitimately enacted. Deliberation is not needed. The direct role for deliberation arising from the need for publicly justified laws is minimal, even on a consensus view. Indeed, convergence gives a need for all the different reasons that citizens have to become known, and deliberation is useful for this, whereas on a consensus view only a limited number of reasons and values are relevant, and citizens might know many of these without engaging in deliberation. More, rather than less, deliberation and persuasion might be needed in order for convergence justifications to be achieved.

Deliberation has an important place within political liberalism. It is a central way that citizens directly manifest respect for one another, and persuade one another of the merits of proposed laws. All the arguments for this equally apply under convergence, and deliberation will still be encouraged if convergence justifications are permitted. Convergence allows at least as much of a role for deliberation as consensus does.

\section{Conclusion}

Convergence justifications are legitimate forms of public justification. They satisfy the requirement, demanded by respect for persons, that laws be justified to every citizen, and the three objections to them that I have considered all fail. As I outlined above, this has significant implications for the constraints applying to the conduct of citizens. These are implications that we should accept. In fact, they might well make political liberalism more attractive to many of its critics, particularly those defending the role of religion in public life.

Acknowledgements This paper originates from my MPhil and PhD research, which were supported by an Arts \& Humanities Research Council Studentship. For numerous helpful comments, I wish to thank my supervisor, Stuart White, and the audience at the Oxford Graduate Political Theory Workshop, particularly Franz Mang and Matthias Brinkmann. This essay was previously shortlisted for the Res Publica postgraduate essay prize 2014. I owe thanks to the anonymous reviewers both of the version of the paper that I submitted for the essay prize and of earlier drafts of this version.

\section{References}

Audi, Robert. 1997. Wolterstorff on religion, politics, and the liberal state. In Religion in the public square: The place of religious convictions in political debate, Robert Audi and Nicholas Wolterstorff, 121-144. London: Rowman \& Littlefield. 
Baccarini, Evlio. 2013. Having a reason and distributive justice in The order of public reason. European Journal of Analytic Philosophy 9: 25-51.

Bird, Colin. 2014. Coercion and public justification. Politics, Philosophy \& Economics 13: 189-214.

Boettcher, James W. 2005. Strong inclusionist accounts of the role of religion in political decision-making. Journal of Social Philosophy 36: 497-516.

Boettcher, James W. 2007. Respect, recognition and public reason. Social Theory and Practice 33: 223-249.

Boettcher, James W., and Jonathan Harmon. 2009. Introduction: Religion and the public sphere. Philosophy \& Social Criticism 35: 5-22.

Bohman, James, and Henry S. Richardson. Liberalism, deliberative democracy, and "reasons that all can accept". The Journal of Political Philosophy 17: 253-274.

Eberle, Christopher J. 2002. Religious conviction in liberal politics. Cambridge: Cambridge University Press.

Eberle, Christopher J. 2007. Religious reasons in public: Let a thousand flowers bloom, but be prepared to prune. St. John's Journal of Legal Commentary 22: 431-443.

Galston, William A. 1991. Liberal purposes: goods, virtues, and diversity in the liberal state. Cambridge: Cambridge University Press.

Gaus, Gerald. 2009. The place of religious belief in public reason liberalism. In Multiculturalism and moral conflict, eds. Maria Dimovia-Cookson and P.M.R. Stirk, 19-37. London: Routledge.

Gaus, Gerald. 2010a. Coercion, ownership, and the redistributive state: Justificatory liberalism's classical tilt. Social Philosophy and Policy 27: 233-275.

Gaus, Gerald. 2010b. On two critics of justificatory liberalism: A response to Wall and Lister. Politics, Philosophy \& Economics 9: 177-212.

Gaus, Gerald. 2011. The order of public reason: A theory of freedom and morality in a diverse and bounded world. Cambridge: Cambridge University Press.

Gaus, Gerald and Kevin Vallier. 2009. The roles of religious conviction in a publicly justified polity: The implications of convergence, asymmetry and political institutions. Philosophy \& Social Criticism 35: 5176.

Habermas, Jürgen. 2006. Religion in the public square. European Journal of Philosophy 14: 1-25.

Klosko, George. 2003. Reasonable rejection and neutrality of justification. In Perfectionism and neutrality: Essays in liberal theory, eds. Steven Wall and George Klosko, 167-189. Oxford: Rowman \& Littlefield.

Laborde, Cécile. 2013. Justificatory secularism. In Religion in a liberal state, eds. Gavin D'Costa, Malcolm Evans, Tariq Modood, and Julian Rivers, 164-186. Cambridge: Cambridge University Press, 2013.

Larmore, Charles. 1999. The moral basis of political liberalism. The Journal of Philosophy 96: 599-625.

Larmore, Charles. 2003. Public reason. In The Cambridge companion to Rawls, ed. Samuel Freeman, 368393. Cambridge: Cambridge University Press.

Lister, Andrew. 2013a. The classical tilt of justificatory liberalism. European Journal of Political Theory 12: 316-326.

Lister, Andrew. 2013b. Public reason and political community. London: Bloomsbury Academic.

Macedo, Stephen. 1997. In defence of liberal public reason: Are slavery and abortion hard cases? American Journal of Jurisprudence 42: 1-29.

Macedo, Stephen. 2010. Why public reason? Citizens' reasons and the constitution of the public sphere. SSRN e-library. http://papers.ssrn.com/sol3/papers.cfm?abstract id=1664085.

Nozick, Robert. 1974. Anarchy, state and utopia. Oxford: Basil Blackwell.

Quong, Jonathan. 2004. The scope of public reason. Political Studies 52: 233-250.

Quong, Jonathan. 2008. Three disputes about public justification: Commentary on Gaus and Vallier. www.publicreason.net/wp-content/PPPS/Fall2008/JQuong1.pdf.

Quong, Jonathan. 2011. Liberalism without perfection. Oxford: Oxford University Press.

Rawls, John. 1999. A theory of justice, revised edition. Cambridge, Mass.: Belknap Press of Harvard University Press.

Rawls, John. 2005. Political liberalism, expanded edition. New York: Columbia University Press.

Schwartzman, Micah. 2011. The sincerity of public reason. The Journal of Political Philosophy 19: 375-398.

Solum, Lawrence B. 1993. Constructing an ideal of public reason. San Diego Law Review 30: 729-762.

Stears, Marc, and Mathew Humphrey. 2012. Public reason and political action: Justifying citizen behaviour in actually-existing democracies. The Review of Politics 74: 285-306. 
Stout, Jeffrey. 2004. Democracy and tradition. Oxford: Princeton University Press.

Swaine, Lucas. 2009. Deliberate and free: Heteronomy in the public sphere. Philosophy and Social Criticism 35: 183-213.

Vallier, Kevin. 2011a. Liberal politics and public faith: A philosophical reconciliation. PhD dissertation, University of Arizona.

Vallier, Kevin. 2011b. Consensus and convergence in public reason. Public Affairs Quarterly 25: 261-279.

Vallier, Kevin. 2014. Liberal politics and public faith: Beyond separation. Oxford: Routledge.

Wall, Steven. 2010. On justificatory liberalism. Politics, Philosophy \& Economics 9: 123-149.

Weithman, Paul J. 1997. Religion and the liberalism of reasoned respect. In Religion and contemporary liberalism, ed. Paul J. Weithman, 1-37. Notre Dame, Ind.: University of Notre Dame Press.

Wolterstorff, Nicholas. 1997. The role of religion in decision and discussion of political issues. In Religion in the public square: The place of religious convictions in political debate, Robert Audi and Nicholas Wolterstorff, 67-120. London: Rowman \& Littlefield.

Wolterstorff, Nicholas. 2007. The paradoxical role of coercion in the theory of political liberalism. Journal of Law, Philosophy and Culture 1: 135-158. 